\title{
The „European Alliance Against Depression" - a four-level intervention programme against depression and suicidality
}

\author{
Ulrich Hegerl ${ }^{1}$, Anna Cibis², Ella Arensman³ ${ }^{3}$ Esa Aromaa4, Chantal van Audenhove ${ }^{5}$, Jean-Hervé Bouleau ${ }^{6}$, Christina M van der \\ Feltz-Cornelis 7, Giancarlo Giupponi ${ }^{8}$, Ricardo Gusmä09 ${ }^{9}$ Maria Kopp ${ }^{10}$, Andrej Marusic ${ }^{11}$, Margaret Maxwell12, Ullrich Meise ${ }^{13}$ \\ Högni Oskarsson ${ }^{14}$, Charles Pull15, Regula Ricka ${ }^{16}$, Armin Schmidtke17, Victor Pérez Sola ${ }^{18}$, Merike Sisask19 \& Lisa Wittenburg20
}

In the European Alliance Against Depression (EAAD), partners from 17 European countries are cooperating with the aim to improve the care of depressed patients and to prevent suicidality. Community based interventions are implemented in different regions comprising activities on the following four levels: 1) cooperation with general practitioners, 2) public relations campaign, 3) community facilitators and 4) high risk groups and selfhelp initiatives. The Nuremberg Alliance Against Depression has provided evidence for the effectiveness of this intervention concept by showing a significant reduction of the number of suicidal acts in the intervention region compared to a control region. The experiences in the 17 European countries showed that this four-level intervention concept with its materials can easily be adapted to different countries and different cultural contexts. According to the Green Paper of the European Commission, the EAAD serves as "best practice" example for an international community based programme preventing suicidality.

\section{Introduction}

The impact of suicide is often underestimated, as it is one of the ten leading causes for death in most countries (Bertolote et al., 2005). According to data from the World Health Organisation, suicide will represent $2,4 \%$ of the global burden of disease worldwide in 2020, compared to $1,8 \%$ in the year 1998 (World Health Organization, 2003). Psychiatric disorders are supposed to be one of the most common reasons for suicide. Autopsy studies have shown that around $90 \%$ of suicides are committed in the context of a psychiatric disorder (Lönnqvist et al., 1988; Mann et al., 2005). The most frequently found disorder is major depression, even though schizophrenia and substance-related disorders were also found to be quite frequent (Bertolote et al., 2003; Brent et al., 1994). Therefore, an important strategy to prevent suicide is to improve the care of depressed patients. In addition, a recent review of effective suicide prevention strategies recommends multilevel interventions as successful prevention approach (Mann et al., 2005).

The European Alliance Against Depression (EAAD) was founded in 2004 with the aim to implement community based 4-level interventions targeting depression and suicidality (www.eaad.net). Partners from 17 countries are working together in this project funded by the European Commission. Evidence for the effectiveness of this intervention concept has been provided by a model project, the Nuremberg Alliance Against Depression (Hegerl et al., 2007). In sharing this concept, the EAAD partners enhance their regional experiences and the exchange leads to constant improvement.

This successful implementation was recognized by the European Commission as an "Example of Best Practice" in the Green Paper "Improving the mental health of the population: Towards a strategy on mental health for the European Union (European Commission 2005).

\section{The experience from the Nurem-} berg Alliance Against Depression

Carried out as a sub-project of the "German Research Network on Depression and Suicidality" (funded by the German Federal Ministry of Education and Research), the "Nuremberg Alliance Against Depression" provided a concept and materials for a community-based intervention targeting depression and suicidality (Hegerl et al., 2006). The project started 2000 with a baseline year, including an intervention region (Nuremberg, 500.000 inhabitants) and a control region (Würzburg, 270.000 inhabitants). In 2001 and 2002, a four-level-intervention programme was carried out in Nuremberg (p. 13). The aim was to optimize the care for depressed patients and thus to reduce suicidality. The following four levels (Fig. 1) were chosen:

Level 1: Cooperation with general practitioners

The majority of depressed patients first consult the general practitioner. Also concerning suicidality, it has been found out that approximately $77 \%$ of people who died from suicide had contact with primary care providers within the year of their death (Luoma et al., 2002). These results emphasize the importance of general practitioners (GPs) for the prevention of suicide.

The intervention with primary care physicians included interactive trainings with the goal to improve the diagnostic and therapeutic skills concerning depression as well as the handling of acute suicidality. In these trainings, the WHO5 as an evaluated screening tool for the identification of depressed patients (Henkel et al., 2003), was recommended and handed over to GPs. Among the many further materials the GPs received was a videotape which could be given to depressed patients by the primary care physicians. The patients had the possibility to take the video home and inform themselves about the disorder.

\footnotetext{
${ }^{1}$ Department of Psychiatry, University of Leipzig, Germany ${ }^{2}$ Department of Psychiatry, University of Leipzig, Germany ${ }^{3}$ National Suicide Research Foundation, Cork, Republic of Ireland ${ }^{4}$ Vaasa Hospital Distict, Psychiatric Unit, Vaasa, Finland ${ }^{5}$ LUCAS - Katholieke Universiteit Leuven, Belgium ${ }^{6}$ Fédération de Psychiatrie, Hôpital René Dubos, Pontoise, France ${ }^{7}$ Trimbos instituut, Utrecht and VU medical Centre Institute of extramural research, Amsterdam, the Netherlands ${ }^{8}$ Autonome Provinz Südtirol, Assessorat für das Gesundheitswesen, Bozen, Italy 9 Universidade Nova de Lisboa, Faculdade de Ciências Médicas, Lisbon, Portugal ${ }^{10}$ Semmelweis University Budapest, Hungary ${ }^{11}$ Insititute of Public Health of the Republic of Slovenia, Ljubljana, Slovenia ${ }^{12}$ Department of Applied Social Science, University of Stirling, Scotland, U.K. ${ }^{13}$ Gesellschaft für Psychische Gesundheit - pro mente tirol, Innsbruck, Austria ${ }^{14}$ Directorate of Health Campaign Against Depression and Suicide, Seltjarnarnes, Iceland ${ }^{15}$ Centre Hospitalier de Luxembourg, Luxembourg ${ }^{16}$ Bundesamt für Gesundheit, Bern, Switzerland ${ }^{17}$ Clinic for Psychiatry and Psychotherapy, University of Würzburg, Germany ${ }^{18}$ Hospital de la Santa Creu i Sant Pau Psychiatry Department, Barcelona, Spain ${ }^{19}$ Estonian-Swedish Mental Health and Suicidology Institute; Estonian Centre of Behavioural and Health Sciences, Tallinn, Estonia ${ }^{20}$ Department of Psychiatry, University of Leipzig, Germany
} 


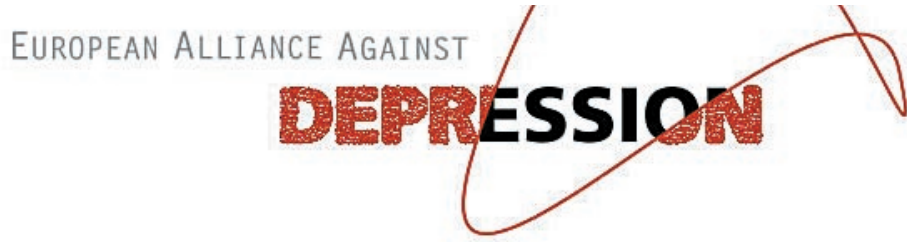

Fig. 1: Multi-level-approach of the „Nuremberg Alliance against Depression“

\section{Level I}

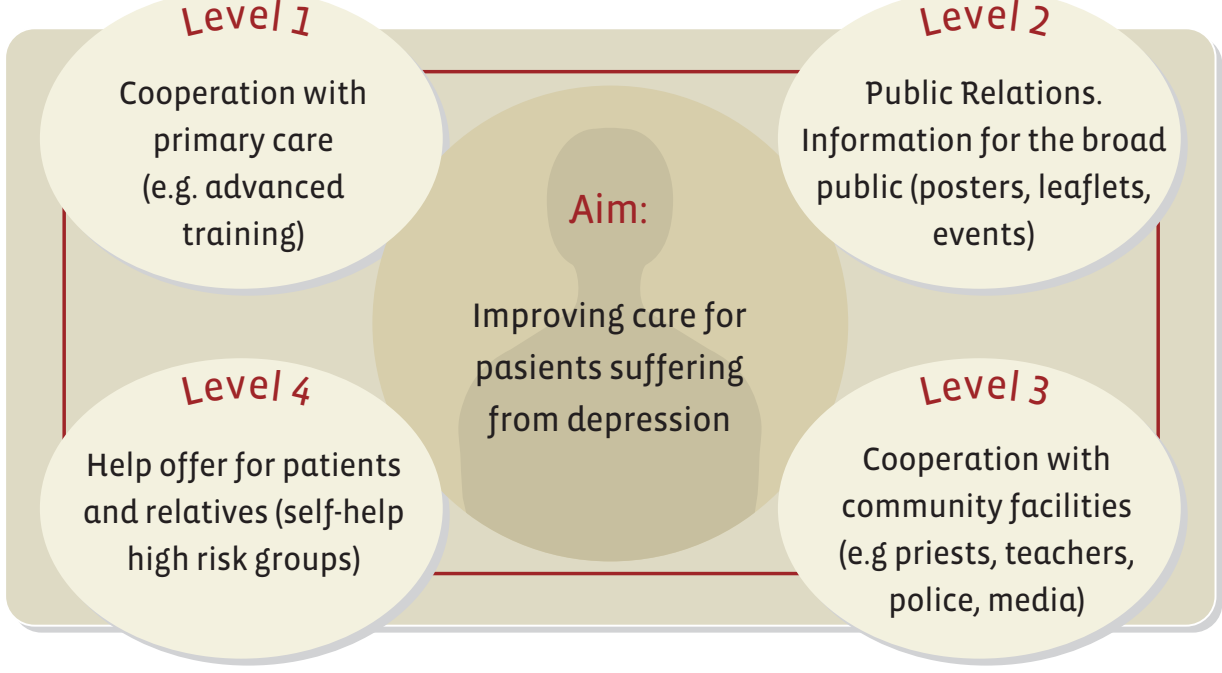

\section{Level 2: Public Relations Campaign}

In addition to the improvement of primary care, another important goal was fighting the stigma towards mental disorders. By conducting a professional public relations campaign, the Nuremberg Alliance Against Depression was aiming at the general public. The goal of the campaign was to address misconceptions and insufficient knowledge about depression and suicidality and thus intensify the professional support of depressed patients. There were three central messages of the media campaign: "Depression is treatable.", "Depression has many faces." and "Depression can affect anyone." Furthermore, the public relations campaign included the distribution of different information materials (leaflets, brochures, videotapes) and the organisation of public information events. Different posters with the central messages were aiming at different target groups by showing distinct motives like an old man or a young couple (Figure 2 ).

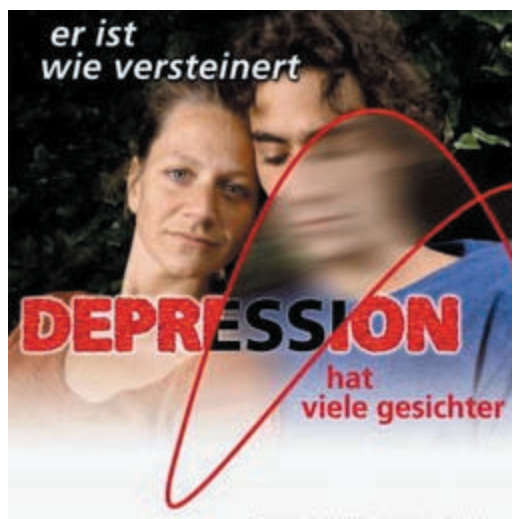

Fig. 2: Campaign poster promoted by „Nuremberg Alliance against Depression“ : Depression has many faces
In addition, there was close cooperation between the local coordinators and the media in the target area. In order to avoid copycat suicides, media guidelines concerning the responsible reporting of suicides were disseminated among the reporters. Referring to the "Werther effect" (Wasserman 1984), they contained recommendations how to report on suicides, e.g. not to sensationalize the act, to avoid descriptions of details, motives and personal background information.

\section{Level 3: Community Facilitators}

Like general practitioners, community facilitators who are in contact with highrisk groups are also influential key individuals for the further treatment of the patients. To improve their knowledge about depression and suicidality, educational trainings were arranged for social workers, clergy, geriatric nurses, teachers, prison workers, pharmacists, policemen and others. The trainings were targeted at the needs and tasks of the different community facilitators. In addition to the trainings, improving the network between the community facilitators (and also the GPs) was another goal of interventions on this level.

\section{Level 4: High risk groups and self-help} groups

Depressed patients and persons who have attempted suicide in their past are considered to be high-risk groups for committing suicide in the future. Offering an emergency card to persons after suicide attempt was one intervention on this level. The card showed a phone number providing access to professional help. Other interventions included supporting self-help initiatives and founding new self-help groups.

\section{Evaluation of the Nuremberg Alliance Against Depression}

The a priori defined outcome was the number of suicidal acts, combining the number of suicides and non-fatal suicidal acts. The primary outcome was chosen, because even for a city like Nuremberg (pop. 500.000), the base rate of suicides is too low and the annual random fluctuations too high in order to allow the statistical detection of even pronounced reduction in suicides.

The number of suicidal acts in Nuremberg decreased from the baseline (2000) by $24.0 \%$ during the two intervention years (2001-2002). An even further decrease by $32 \%$ was observed in the followup year (Figure 3 ). These results represent a statistically significant and clinically highly relevant reduction in suicidal acts in Nuremberg compared to the control region where the rate remained stable (Hegerl et al., 2006). The reduction was even more pronounced $(-53 \%)$ when looking only at the five most drastic suicide attempt methods.

Having received a lot of interest, the original project has spread all over Germany, so that actually 40 regions conduct their own four-level programmes under the umbrella of the "German Alliance Against Depression".

\section{Further improvement and evalu- ation of the 4-level intervention concept within EAAD}

The interventions in the participating European regions are oriented along the lines of the pilot project in Nuremberg and the majority of material and instruments have been adapted. Furthermore, the existing instruments have been completed by material concerning depression and suicidality, already available in the different regions. The result is a catalogue of "best practice materials", which is continuously being updated. In terms of evaluation, the EAAD partners have also 


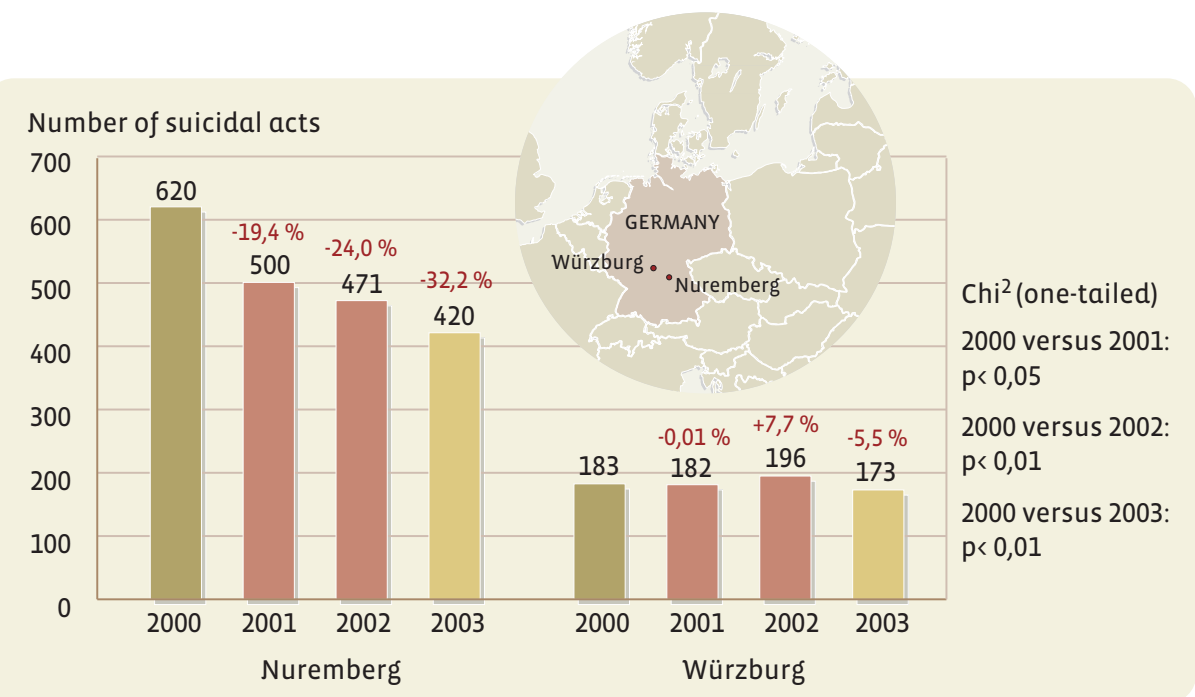

Fig. 3. Significant reduction of suicidal acts in Nuremberg compared to the control region Würzburg (2000: Baseline, 2001/2002: Intervention, 2003: Follow-Up)

defined a set of evaluation indicators for the network consisting of the following criteria: number of completed suicides, number of suicide attempts, prescription rates of psycho-pharmaceutical drugs (mainly antidepressants), measurement of training effects, and recording in changes in attitudes of the general public towards depression and suicidality. Even though the main objective of the EAAD funding is the implementation of action programmes, most partners have gathered baseline data from 2004-2005 on and further evaluate systematically training effects among GPs and community facilitators as well as prescription data.

\section{The EAAD-Network: Experiences and Perspectives}

The "best practice" catalogues for common intervention programmes and evaluation have already shown to some extent how the EAAD network partners manage working together. Due to different structures of health care and social systems in the participating countries, the 4-level intervention programme cannot be implemented in terms of a uniform approach. Rather, the overall programme of the EAAD enables the partners to apply the concept to varying health systems. Thus, the idea of a multilevel intervention remains the same in all countries, but in some it is integrated into other mental health initiatives and in others it represents an own project. Also, the structures are individually different: While some countries started their initiative from the bottom up in one region and are planning to extend their activities to the whole country, comparable to the "German Alliance Against Depression", other
European partners directly started in terms of a top-down approach with a nationwide initiative, like Iceland. In spite of these individual approaches, the partners have in common their great interest to continue their work and in many cases to expand the regional Alliances Against Depression nationwide. In Switzerland, Austria, Italy, Estonia and Hungary for example, the dissemination to local regions already takes place. While encouraging on the one hand, this growth represents a new challenge for the EAAD network on the other. But the cooperation until now has shown that following one common intervention approach and realizing it in a regionally individual way remains a promising procedure. Further promising are the strong synergistic effects of the 4-level intervention, resulting from being simultaneously active at four levels. In conclusion, the EAAD may serve as an example of how evidence based and international community based "best practice" models for improving the care of depressed patients and suicidal persons can be implemented.

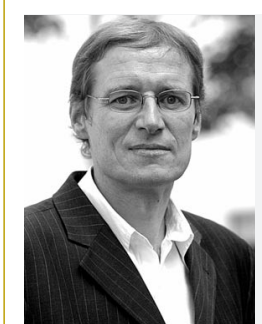

Ulrich Hegerl, MD, is Chair and Medical Director of the Department of Psychiatry, Leipzig University, in Leipzig, Germany. His research activities include implementation and evaluation of suicide prevention measures, investigation of optimized treatment methods for minor and subthreshold depression in primary care settings, and research regarding the mole-cular genetic aspects of depressive disorders. He is the Project coordinator of the European Alliance Against Depression (EAAD) and also the Principal Investigator for the EAAD study regarding intervention for depression at the primary care, public information, community facilitator, and high-risk group levels.

\section{References}

Bertolote, J. M. \& Fleischmann, A. (2005). Suicidal behavior prevention: WHO perspectives on research. Am J Med Genet.C Semin. Med Genet., 133, 8-12.

Bertolote, J. M., Fleischmann, A., De Leo, D., \& Wasserman, D. (2003). Suicide and mental disorders: do we know enough? Br J Psychiatry, 183, 382-383.

Brent, D. A., Johnson, B. A., Perper, J., Connolly, J., Bridge, J., Bartle, S., \& Rather, C. (1994). Personality disorder, personality traits, impulsive violence, and completed suicide in adolescents. J Am Acad Child Adolesc Psychiatry, 33, 1080-1086.

European Commission. (2005). Green Paper: Improving the mental health of the population: Towards a strategy on mental health for the European Union on mental health.

Hegerl, U., Althaus, D., Schmidtke, A., \& Niklewski, G. (2006a). The alliance against depression: 2-year evaluation of a community-based intervention to reduce suicidality. Psychol Med, 36, 1225 1233.

Hegerl, U., Althaus, D., Schmidtke, A., \& Niklewski, G. (2006b). The alliance against depression: 2 -year evaluation of a community-based intervention to reduce suicidality. Psychol Med, 36, 1225-1233.

Hegerl, U., Wittmann, M., Arensman, E., van Audenhove, C., Bouleau, J. H., Feltz-Cornelis, C., Gusmao, R., Kopp, M., Lohr, C., Maxwell, M., Meise, U., Mirjanic, M., Oskarsson, H., Sola, V. P., Pull, C., Pycha, R., Ricka, R., Tuulari, J., Varnik, A., \& Pfeiffer-Gerschel, T. (2007). The 'European Alliance Against Depression (EAAD)': A multifaceted, community-based action programme against depression and suicidality. World J Biol Psychiatry, 1-8.

Henkel, V., Mergl, R., Kohnen, R., Maier, W., Moller, H. J., \& Hegerl, U. (2003). Identifying depression in primary care: a comparison of different methods in a prospective cohort study. BMJ, 326, 200-1.

Lönnqvist, J. \& Koskenvuo, M. (1988). Mortality in depressive disorders; a 3-year prospective followup study in Finland. In: Helgason, T. D. R.,

Depressive illness: Prediction of course and outcome (126-130).

Luoma, J. B., Martin, C. E., \& Pearson, J. L. (2002). Contact with mental health and primary care providers before suicide: a review of the evidence. Am J Psychiatry, 159, 909-916.

Mann, J. J., Apter, A., Bertolote, J., Beautrais, A., Currier, D., Haas, A., Hegerl, U., Lonnqvist, J., Malone, K., Marusic, A., Mehlum, L., Patton, G., Phillips, M., Rutz, W., Rihmer, Z., Schmidtke, A., Shaffer, D., Silverman, M., Takahashi, Y., Varnik, A., Wasserman, D., Yip, P., \& Hendin, H. (2005). Suicide prevention strategies: a systematic review. JAMA, 294, 2064-2074.

Wasserman, I. M. (1984). Imitation and suicide: A reexamination of the Werther effect. American Sociological Review, 49, 427-436.

World Health Organization. (2003). The World Health Report 2003: Shaping the future. 